\title{
ALPHA-TOCOPHEROL-DEPENDENT SALT TOLERANCE IS MORE RELATED WITH AUXIN SYNTHESIS RATHER THAN ENHANCEMENT ANTIOXIDANT DEFENSE IN SOYBEAN ROOTS
}

\author{
Seda Sereflioglu, Burcu Seckin Dinler* and Eda Tasci \\ Department of Biology, Faculty of Art and Science, Sinop University, Sinop, Turkey
}

(Received: August 15, 2016; accepted: November 8, 2016)

\begin{abstract}
In this paper, we describe the alleviated effects of alpha-tocopherol $(\alpha-\mathrm{T})$ on oxidative damage and its possible role as a signal transmitter in plants during salt stress. The results show that exogenously applied $\alpha$-T under salt stress increased root length and weight, but reduced hydrogen peroxide $\left(\mathrm{H}_{2} \mathrm{O}_{2}\right)$, superoxide anion radical $\left(\mathrm{O}_{2}{ }^{-}\right)$and malondialdehyde (MDA) content in soybean roots. The proline content was reduced by $\alpha$-T treatment. Interestingly, endogenous auxin (IAA) level was significantly increased after $\alpha-T$ application as compared to salt stress alone. Moreover, $\alpha-T$ reduced significantly superoxide dismutase (SOD) enzyme and isoenzyme activity but upregulated peroxidase (POX) 2, 3 and glutathione-stransferase (GST) 1, 3 isoenzyme expression. However, ascorbate peroxidase (APX) enzyme activity was not affected at all. Consequently, the results show that $\alpha$-T serves as a signal molecule under salinity from leaves to roots by increasing remarkably endogenous IAA levels and increasing partially antioxidant activity in roots.
\end{abstract}

Keywords: Alpha-tocopherol - IAA - salinity - soybean - antioxidant

\section{INTRODUCTION}

Alpha-tocopherol ( $\alpha$-T, vitamin $\mathrm{E})$ is a lipophilic membrane-located antioxidant with a low molecular weight; its level varies in different tissues. In plants, tocopherols are synthesized and localized in plastids [2]. The improve membrane stability and protect cell membranes against oxidative damage by quenching reactive oxygen species (ROS) [3] and modulate signal transduction [32] and phytohormones [27]. This was also summarized in a previous study [14]. $\alpha$-T preserves PSII from photo-inactivation and protects membrane lipids from photo-oxidation [16]. Furthermore, jasmonic acid and ethylene signaling pathways are downregulated in mature leaves of the saltstressed Arabidopsis vte4 mutant which are impaired in tocopherol biosynthesis [6]. Some studies reported that exogenous tocopherol application protects plants from

Abbreviations: $\alpha$-T: alpha-tocopherol; APX: ascorbate peroxidase; GST: glutathione-s-transferase; $\mathrm{H}_{2} \mathrm{O}_{2}$ : hydrogen peroxide; IAA: auxin; MDA: malondialdehyde; $\mathrm{O}_{2}{ }^{-}$: superoxide anion radical; POX: peroxidase; ROS: reactive oxygen species; SOD: superoxide dismutase.

*Corresponding author; e-mail address: burcu_sec@hotmail.com 
stress conditions. According to the studies mentioned above, $\alpha$-T may induce plant hormones under stress conditions, but the reason for this is not clear. Auxin (IAA) is known as a key hormone in plants with control apical dominance, leaf primordia, as well as shoot and root elongation [38]. In recent years, however, some reports have indicated that it also functions under stress conditions [29]. In general, endogenous IAA levels were reduced in plants under salinity stress [25] but contradictory results were also reported in roots and leaves [24]. It was suggested that changes in IAA levels under salinity led to regulation of root structure and ROS and ABA responsive genes in plants [34]. To our knowledge, this is the first work focusing on the interaction between exogenous tocopherol application and endogenous auxin level change.

The present study was undertaken to help us evaluate the relation between hormones and tocopherol in plants. The most important question was, in which way sends tocopherol signal from leaves to roots to increase the IAA level and promote salt stress response, and whether it could be considered as a signal transmitter in growth and response to salinity in the plant from leaves to roots.

\section{MATERIAL AND METHODS}

\section{Plant materials and growth conditions}

Soybean (Glycine $\max$ L. Merr.) seeds were obtained from a commercial provider (May, Bursa, TR). The seeds were sown in plastic trays $(10 \mathrm{~cm} \times 14 \mathrm{~cm})$ filled with soil under dark conditions. After germination, seedlings were placed into a growth chamber at $25^{\circ} \mathrm{C}$ with $16 \mathrm{~h} / 8 \mathrm{~h}$ day/night photoperiod and light intensity of $500 \mu \mathrm{mol}$ $\mathrm{m}^{-2} \mathrm{~s}^{-1}$ with $1 / 2$ Hoagland solution for 2 weeks. Seedlings were pre-treated with a 2.5 $\mathrm{mM}$ concentration of $\alpha$-T by spraying for 3 days at $24 \mathrm{~h}$ interval. On the third day, leaves that were exposed to $(\alpha-\mathrm{T})(0.5,1.00,1.50,2.00,2.50,3.00,3.50$ and 4.00 $\mathrm{mM}$ ) and controls were treated with $200 \mathrm{mM} \mathrm{NaCl}$. This concentrations were determined by previous studies (Fig. 1). Altogether, there were four different, experimental groups: control $(\mathrm{C})$, tocopherol $(\alpha-\mathrm{T})$, treated salt stressed $(\mathrm{NaCl})$, and tocopherol treated and salt stressed $(\alpha \mathrm{T}+\mathrm{NaCl})$. After exposition, roots were harvested at $0 \mathrm{~h}$ and $72 \mathrm{~h}$ and stored at $-80{ }^{\circ} \mathrm{C}$.

\section{Experimental approaches}

IAA level was detected according to Flores et al. [12]. The level of lipid peroxidation in leaf samples was determined in terms of malondialdehyde (MDA) content according to Madhava Rao and Sresty [26]. Hydrogen peroxide $\left(\mathrm{H}_{2} \mathrm{O}_{2}\right)$ levels were determined according to the method of Velikova et al. [37]. The proline content of the leaves was determined by the method described by Claussen [8]. $\alpha$-T content was determined in according to Winifred et al. [39], using a Hewlett Packard 1100 (HP 
1100 HPLC). Scavenging ability of superoxide anion radical was evaluated by the method of negative staining technique [9].

Superoxide dismutase (SOD; EC 1.15.1.1) activity was assayed by its ability to inhibit photochemical reduction of nitrotetrazolium blue chloride (NBT) at $560 \mathrm{~nm}$ [4]. Ascorbate peroxidase (APX; EC 1.11.1.11) activity was measured according to Herzog et al. [19]. Peroxidase (POX; EC 1.11.1.7) activity was determined according to the method of Hernandez et al. [18]. Glutathione-s-transferases (GST; EC 2.5.1.18) activity was determined by following the increase in absorbance at $340 \mathrm{~nm}$ due to the formation of the conjugate1-chloro-2,4-dinitrobenzene (CDNB) using reduced glutathione $(\mathrm{GSH})$ as substrate [15]. Total soluble protein contents of the enzyme extracts were determined according to Bradford et al. [5].

Equal amounts of protein were subjected to non-denaturing polyacrylamide gel electrophoresis (PAGE) as described by Laemmli [23], excluding the omission of sodium dodecyl sulfate. For the densitometric analyses of SOD, APX, POX and GST activity, the activities of control plants were considered as $100 \%$, and the percentages of the control values for each treatment are shown in Figures 4-7.

\section{RESULTS}

\section{Growth analysis}

Salt stress $(\mathrm{NaCl})$ led to a reduction in root length $(50 \%)$, and did not affect the shoot length. Alpha-tocopherol under salt stress $(\alpha-\mathrm{T}+\mathrm{NaCl})$ treatment increased root length by $50 \%$, whereas shoot was longer by $9 \%$ as compared to $\mathrm{NaCl}$ (Table 1 ).

Table 1

The changes in root length $(\mathrm{cm})$, dry weight $(\mathrm{g})$, in soybean (Glycine max L.) roots under pre-treatment of $\alpha$-T under salt stress

\begin{tabular}{|c|c|c|c|c|}
\hline Groups & $\mathrm{C}$ & $\alpha \mathrm{T}$ & $\mathrm{NaCl}$ & $\alpha \mathrm{T}+\mathrm{NaCl}$ \\
\hline \multicolumn{5}{|c|}{ Root length } \\
\hline $72 \mathrm{~h}$ & $15.1 \pm 1.10^{\mathrm{a}}$ & $19.0 \pm 0.8^{\mathrm{b}}$ & $7.0 \pm 1.0^{\mathrm{c}}$ & $10.0 \pm 1.0^{\mathrm{d}}$ \\
\hline \multicolumn{5}{|c|}{ Dry weight } \\
\hline $72 \mathrm{~h}$ & $0.015 \pm 0.02^{\mathrm{a}}$ & $0.014 \pm 0.01^{\mathrm{a}}$ & $0.0075 \pm 0.02^{\mathrm{b}}$ & $0.010 \pm 0,01^{\mathrm{c}}$ \\
\hline
\end{tabular}

Control (C), Alpha tocopherol $(\alpha-\mathrm{T})$ Salts stress $(\mathrm{NaCl})$, Alpha tocopherol $+\mathrm{NaCl}(\alpha-\mathrm{T}+\mathrm{NaCl})$. Columns with different letters represent significantly different $(P<0.05)$ values.

\section{Hydrogen peroxide $\left(\mathrm{H}_{2} \mathrm{O}_{2}\right)$ and lipid peroxidation (MDA)}

$\mathrm{NaCl}$ stress increased $\mathrm{H}_{2} \mathrm{O}_{2}$ level by $19 \%$, while $\alpha-\mathrm{T}+\mathrm{NaCl}$ reduced this level by $41 \%$. $\mathrm{NaCl}$ application increased MDA content by $16 \%$ in soybean roots as compared to the control group (C), but $\alpha-\mathrm{T}+\mathrm{NaCl}$ alleviated it by $26 \%$ (Fig. 2A, B). 


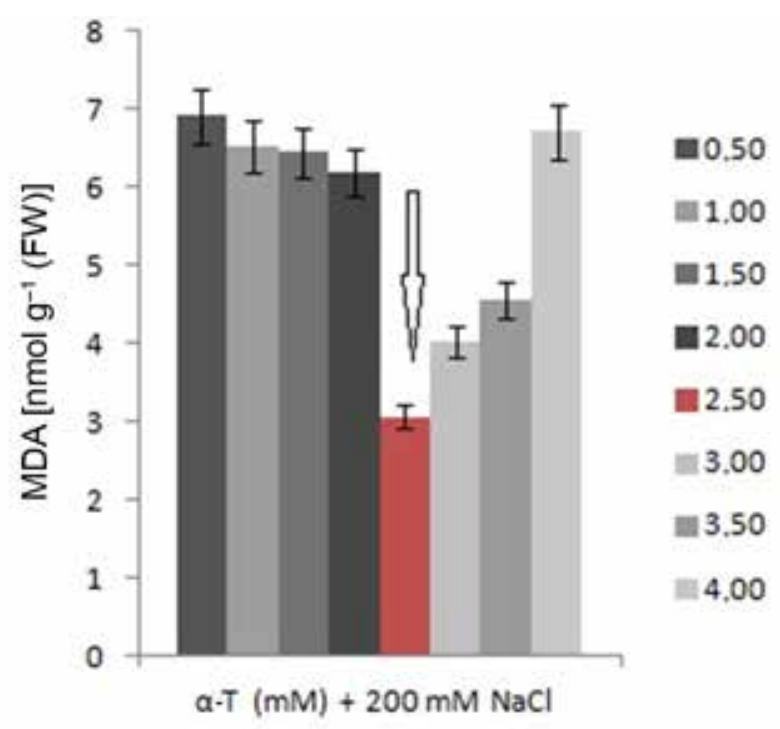

Fig. 1. The effects of different concentrations on malondialdehyde (MDA) content in soybean roots under $\mathrm{NaCl}$ stress

\section{Proline content and superoxide anion radical}

$\mathrm{NaCl}$ stress increased proline content by $31 \%$ in soybean roots as compared to the control group (C), but $\alpha-\mathrm{T}+\mathrm{NaCl}$ reduced it by $40 \%$ as compared to $\mathrm{NaCl}$ treatment. $\mathrm{NaCl}$ application also increased $\mathrm{O}_{2}{ }^{-}$by $10 \%$ in soybean roots as compared to control group (C), but $\alpha-\mathrm{T}+\mathrm{NaCl}$ reduced this level by $10 \%$ as compared to $\mathrm{NaCl}$ stress alone (Fig. 2C, D).

\section{Endogenous $(\alpha-T)$ content}

$\mathrm{NaCl}$ stress alone increased $\alpha$-T content by $16 \%$, while it was 4 -fold higher (64\%) following $\alpha-\mathrm{T}+\mathrm{NaCl}$ application (Table 2).

Table 2

The changes in $\alpha$ tocopherol content ( $\mu \mathrm{g} / \mathrm{g}$ ) in soybean (Glycine max L.) leaves under pre-treatment of $\alpha$-T under salt stress

\begin{tabular}{|c|c|c|c|c|}
\hline Groups & $\mathrm{C}$ & $\alpha-\mathrm{T}$ & $\mathrm{NaCl}$ & $\alpha-\mathrm{T}+\mathrm{NaCl}$ \\
\hline$\alpha-\mathrm{T}(\mu \mathrm{g} / \mathrm{g})$ & \multicolumn{5}{|l|}{} \\
\hline $0 \mathrm{~h}$ & $1.3 \pm 0.05^{\mathrm{a}}$ & $2.5 \pm 0.07^{\mathrm{b}}$ & & \\
\hline $72 \mathrm{~h}$ & $1.2 \pm 0.08^{\mathrm{a}}$ & $3.7 \pm 0.05^{\mathrm{b}}$ & $1.4 \pm 0.0^{\mathrm{a}}$ & $2.3 \pm 0.05^{\mathrm{c}}$ \\
\hline
\end{tabular}

Control (C), Alpha tocopherol $(\alpha-\mathrm{T})$ Salts stress $(\mathrm{NaCl})$, Alpha tocopherol $+\mathrm{NaCl}(\alpha-\mathrm{T}+\mathrm{NaCl})$. Columns with different letters represent significantly different $(P<0.05)$ values. 

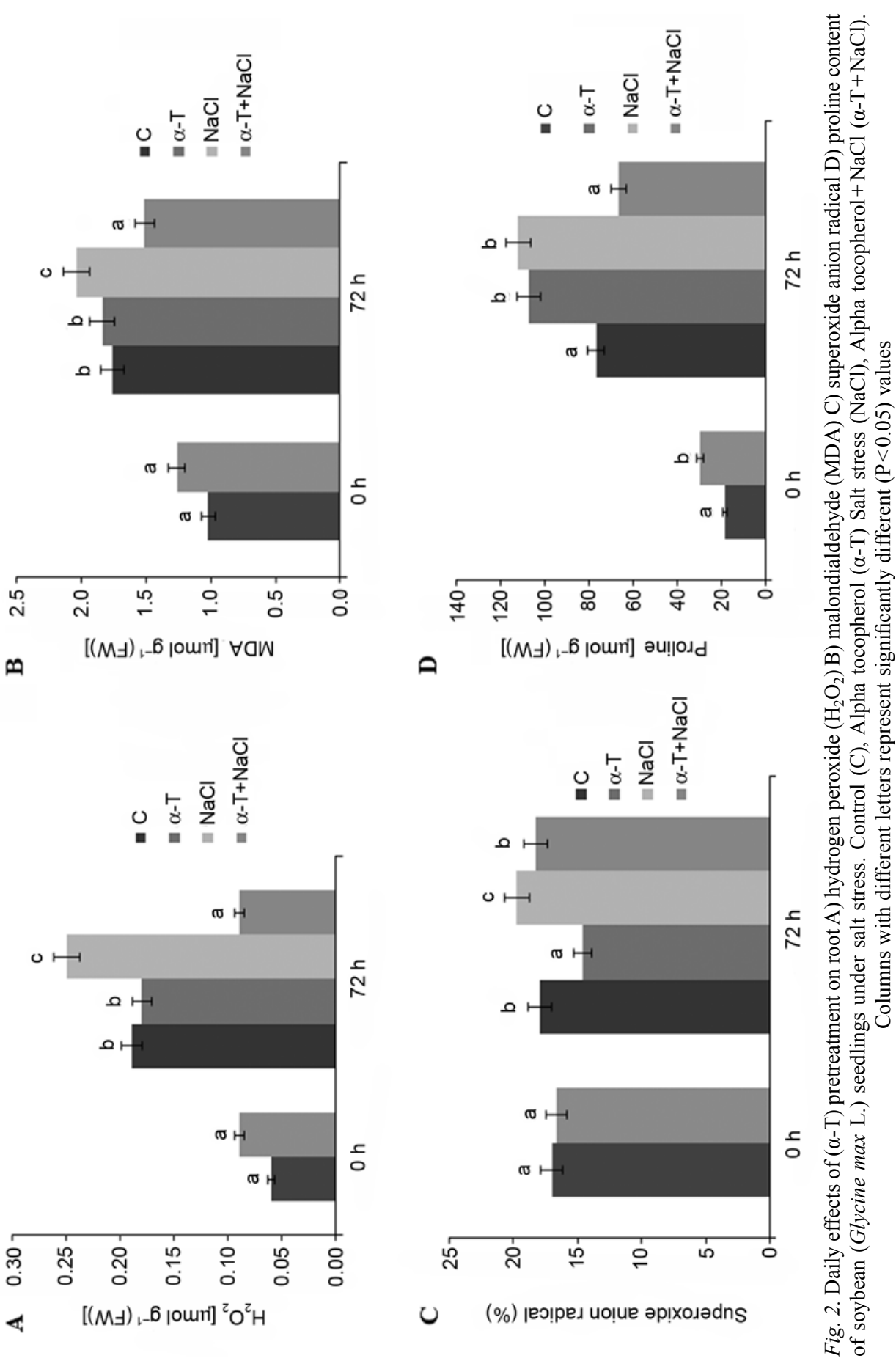

Acta Biologica Hungarica 68, 2017 


\section{Endogenous IAA level}

Application of alone $\alpha$-T increased IAA level by 5 -fold as compared to the control group (C). However, IAA level was increased to 4.2 -fold in soybean roots under salinity. It was determined that $\alpha-\mathrm{T}+\mathrm{NaCl}$ increased IAA level to 3.6-fold as compared to $\mathrm{NaCl}$ stress alone (Fig. 3).

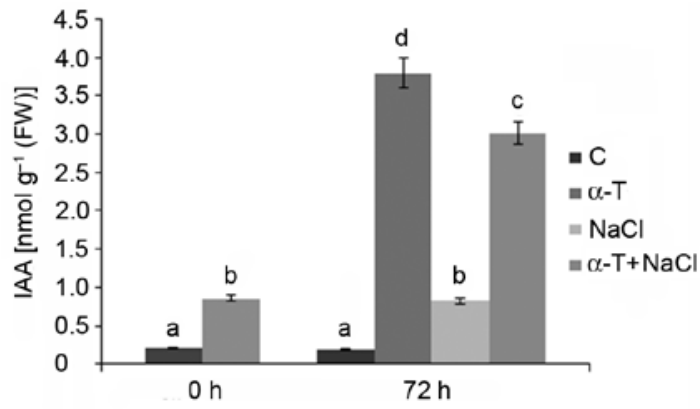

Fig. 3. Daily effects of $(\alpha-T)$ pretreatment on root auxin (IAA) level of soybean (Glycine max L.) seedlings under salt stress. Control (C), Alpha tocopherol $(\alpha-\mathrm{T})$, Salt stress $(\mathrm{NaCl})$, Alpha tocopherol $+\mathrm{NaCl}$

$(\alpha-\mathrm{T}+\mathrm{NaCl})$. Columns with different letters represent significantly different $(\mathrm{P}<0.05)$ values

\section{Antioxidant enzymes}

Salt stress reduced SOD enzyme activity by $71 \%$ as compared to the control group (C). $\alpha-\mathrm{T}+\mathrm{NaCl}$ reduced SOD enzyme activity by $40 \%$. Salt stress also reduced GST enzyme activity by $21 \%$ as compared to the control group (C), whereas $\alpha-\mathrm{T}+\mathrm{NaCl}$ increased GST enzyme activity by $47 \%$. $\mathrm{NaCl}$ application increased POX enzyme activity by $15 \%$ in soybean roots, whereas $\alpha-\mathrm{T}+\mathrm{NaCl}$ increased POX enzyme activity by $93 \%$ as compared to $\mathrm{NaCl}$ stress alone. Otherwise, APX enzyme activity was not effected by $\mathrm{NaCl}$ treatment but increased under $\alpha$-T treatment (Figs 4-7).

A

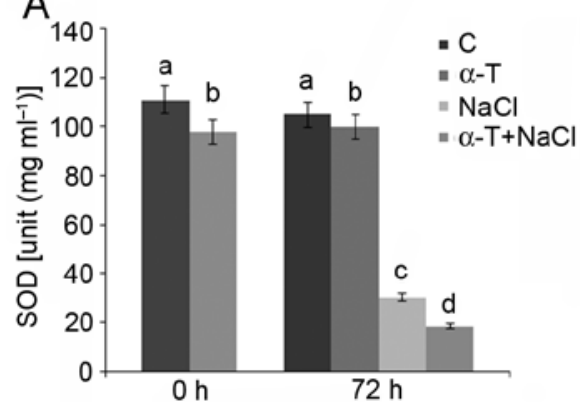

B

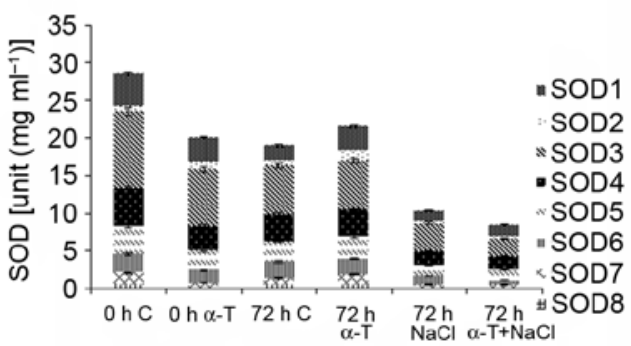

Fig. 4. Daily effects of ( $\alpha-\mathrm{T})$ pretreatment on root activity staining, (A) total superoxide dismutase (SOD) activity and (B) \% induction of SOD isoenzymes in soybean (Glycine max L.) seedlings under salt stress. Control (C), Alpha tocopherol $(\alpha-\mathrm{T})$, Salt stress $(\mathrm{NaCl})$, Alpha tocopherol $+\mathrm{NaCl}(\alpha-\mathrm{T}+\mathrm{NaCl})$. Columns with different letters represent significantly different $(\mathrm{P}<0.05)$ values 

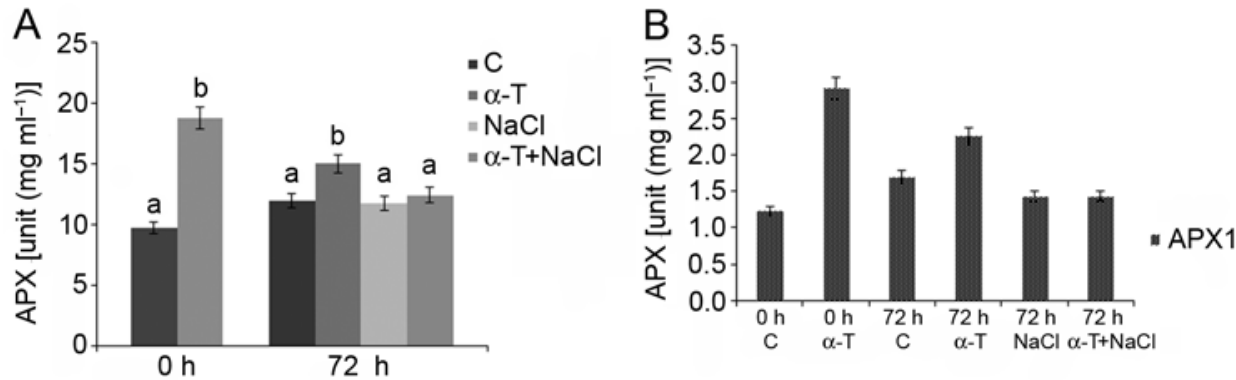

Fig. 5. Daily effects of $(\alpha-T)$ pretreatment on root activity staining, A) total ascorbate peroxidase (APX) activity and B) \% induction of APX isoenzymes in soybean (Glycine max L.) seedlings under salt stress. Control (C), Alpha tocopherol $(\alpha-\mathrm{T})$ Salt stress $(\mathrm{NaCl})$, Alpha tocopherol $+\mathrm{NaCl}(\alpha-\mathrm{T}+\mathrm{NaCl})$. Columns with different letters represent significantly different $(\mathrm{P}<0.05)$ values
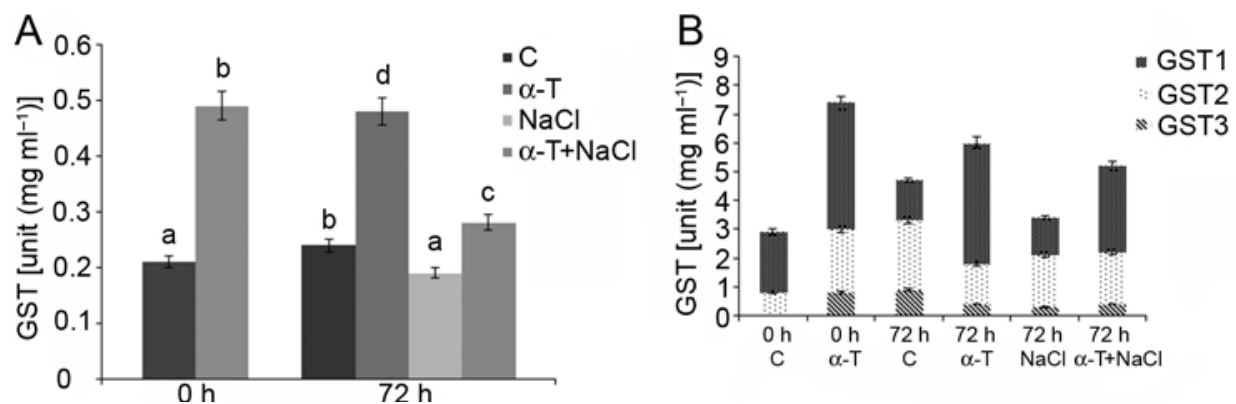

Fig. 6. Daily effects of $(\alpha-T)$ pretreatment on root activity staining, A) total glutathione $s$-transferase (GST) activity and B) \% induction of GST isoenzymes in soybean (Glycine max L.) seedlings under salt stress. Control (C), Alpha tocopherol $(\alpha-\mathrm{T})$, Salt stress $(\mathrm{NaCl})$, Alpha tocopherol $+\mathrm{NaCl}(\alpha-\mathrm{T}+\mathrm{NaCl})$.

Columns with different letters represent significantly different $(\mathrm{P}<0.05)$ values

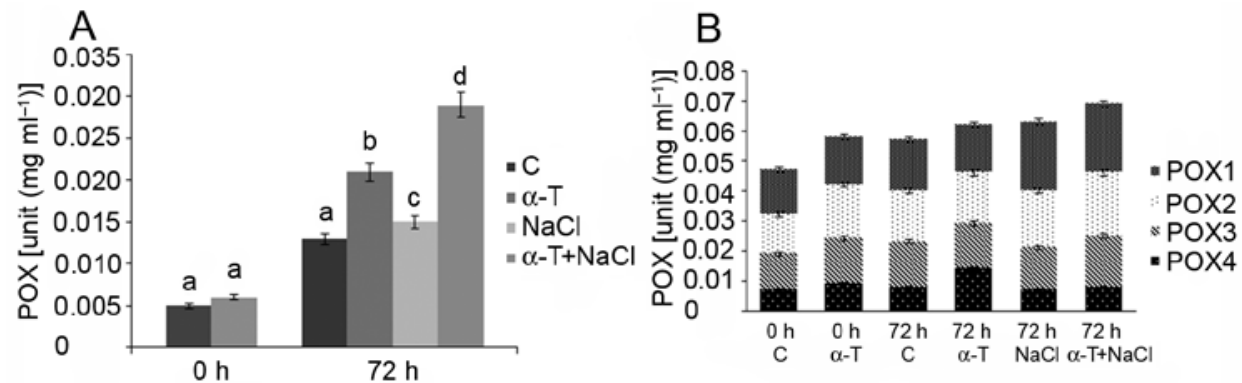

Fig. 7. Daily effects of $(\alpha-\mathrm{T})$ pretreatment on root activity staining, A) total peroxidase (POX) activity and B) \% induction of POX isoenzymes in soybean (Glycine max L.) seedlings under salt stress. Control (C), Alpha tocopherol $(\alpha-\mathrm{T})$, Salt stress $(\mathrm{NaCl})$, Alpha tocopherol $+\mathrm{NaCl}(\alpha-\mathrm{T}+\mathrm{NaCl})$. Columns with different letters represent significantly different $(\mathrm{P}<0.05)$ values 


\section{DISCUSSION}

In the present study, it was shown that salt application decreased only the root length as compared to the control group. In parallel with our result, it was reported that increased $\mathrm{NaCl}$ concentrations led to decrease in soybean root length [36]. Interestingly, according to the results obtained by us, $\alpha$-T application under salt stress increased root length in soybean plants. As shown in a previous study, $\alpha-\mathrm{T}$ application also increased growth in wheat plants under heat stress [22].

As to our results, the significiant reduction (26\%) in MDA content can be regarded as a sign that $\alpha-T$ may protect plant cell membranes by two mechanisms. Firstly, it is known that $\alpha$-tocopherol protects PSII from photo-inactivation and membrane lipids by quenching singlet oxygen [13]. $\mathrm{O}_{2}{ }^{-}$occur in all aerobic cells by molecular oxygen $\left(\mathrm{O}_{2}\right)$ and it is important for $\mathrm{H}_{2} \mathrm{O}_{2}$ sources and reacts as a reducing agents for transition metals [1]. Secondly, exogenous $\alpha$-tocopherol treatment increases antioxidant capacity and protects plants from oxidative damage [27]. As shown in Figure 2A, C, salt treatment increases $\mathrm{H}_{2} \mathrm{O}_{2}$ and $\mathrm{O}_{2}{ }^{-}$level in soybean roots while $\alpha$-T application reduces them.

In the present study, salt treatment reduced SOD enzyme activity in soybean roots. However, in case of $\alpha-\mathrm{T}+\mathrm{NaCl}$, SOD enzyme activity decreased by $40 \%$ as compared to salt stress alone. As described earlier, tocopherol-treated plants suffer significantly lower oxidative stress as a result of its role in quenching ROS and upregulating antioxidant enzymes [29]. As mentioned above, in our present study, SOD enzyme can be replaced by tocopherol using its antioxidant capacity. On the other hand, significantly decreased SOD enzyme activity in the roots could mean that tocopherol may induce a signal pathway in roots if it is applied on the leaves of soybean plant. Otherwise the elevating effects of salt stress on APX enzyme activity have been reported in numerous studies [18]. However, in the present study, both $\mathrm{NaCl}$ and $\alpha-\mathrm{T}+\mathrm{NaCl}$ did not affect APX enzyme activity. $\alpha-\mathrm{T}$ treatment increased GST enzyme activity whilst salt stress decreased it. In contrast, a previous study reported that GST enzyme activity was increased in tomato plants under salt stress [13]. This contradiction could be explained with different plant species and salt concentrations. In our study, POX enzyme activity was increased under both $\mathrm{NaCl}$ and $\alpha-\mathrm{T}+\mathrm{NaCl}$. In accordance with this result, exogenous tocopherol application increased POX enzyme activity under salt stress in bean plants [34].

Earlier studies have reported contradictory results regarding IAA level and salt stress in plants. Under $\mathrm{NaCl}$ stress, endogenous IAA level was reduced in roots [14], meanwhile, YUC genes, which are responsible for IAA biosynthesis in Arabidopsis, are upregulated under water stress [24]. This latter finding was attributed to the fact that $Y U C$ genes confer drought tolerance, independently of IAA biosynthesis by a thiol-reductase activity [7]. Apart from this, it was reported that IAA can promote drought tolerance by modulating ROS metabolism and inducing ABA responsive gene expression [35]. Tocopherols are also regulated by plant hormones, and they, in turn, can increase hormone levels. It is suggested in a previous study that auxin biosynthesis with tocopherol application could occur from the $Y U C$ gene [7]. Tocopherol 
treatment may have induced these genes in the roots of soybean specifically. So, increased IAA may have induced salt tolerance with tocopherol application. On the other hand, ethylene biosynthesis gene expression was downregulated in tocopherol deficient Arabidopsis vte4 mutant plants under salt stress [6]. Nevertheless, higher level of ABA, JA and ethylene precursor 1-aminocyclopropane-1-carboxylic acid (ACC) was reported in vtel Arabidopsis mutant which is deficient in $\alpha$-tocopherol under salt stress [11]. Our study is the first reporting that tocopherol plays a role as a signal molecule from leaves to roots by increasing endogenous IAA levels. Apart from other biochemical changes (reduced MDA, superoxide radical, $\mathrm{H}_{2} \mathrm{O}_{2}$ and proline, increasing POX and GST enzyme activity), we also observed that increased IAA levels in roots occurring due to tocopherol application improved salt tolerance in soybean roots. This result showed that tocopherol treatment was partially effective on the antioxidant defense system and it suggests another mechanism which could be contributed to the enhanced salt tolerance in soybean roots. Otherwise it was demonstrated that tocopherol may act instead of proline and superoxide dismutase enzyme. For this reason, more advanced molecular research should be done to determine how the root cells could perceive tocopherol-induced signals to notify stress via leaves in plants.

\section{REFERENCES}

1. Ahmad, P., Jaleel, C. A., Salem, M. A., Nabi, G., Sharma, S. (2010) Roles of enzymatic and non enzymatic antioxidants in plants during abiotic stress. Crit. Rev. Biotechnol. 30, 161-175.

2. Arango, Y., Heise, K. P. (1998) Localization of alpha-tocopherol synthesis in chromoplast envelope membranes of Capsicum annuum L. fruits. J. Exp. Bot. 49, 1259-1262.

3. Asada, K. (1999) The water-water cycle in chloroplasts: Scavenging of active oxygens and dissipation of excess photons. Annu. Rev. Plant Physiol. Plant Mol. Biol. 50, 601-639.

4. Beauchamp, C., Fridovich, I. (1973) Isozymes of superoxide dismutase from wheat germ. Biochimica et Biophysica Acta 317, 50.

5. Bradford, M. M. (1976) A rapid and sensitive method for the quantization of microgram quantities of protein utilizing the principle of the protein-dye binding. Analytical Biochem. 72, 248-254.

6. Cela, J., Chang, C., Munne-Bosh, S. (2011) Accumulation of $\gamma$-rather than $\alpha$-tocopherol alters ethylene signaling gene expression in the vte4 mutant of Arabidopsis thaliana. Plant Cell Physiol. 52, $1389-1400$

7. Cha, J. Y., Kim, W. Y., Kang, S. B., Kim. J. I., Baek, D., Jung, I. J., Kim, M. R., Li, N., Kim, H. J., Nakajima, M., Asami, T., Sabir, J. S., Park, H. C., Lee, S. Y., Bohnert, H. J., Bressan, R. A., Pardo, J. M., Yun, D. J. (2015) A novel thiol-reductase activity of Arabidopsis YUC6 confers drought tolerance independently of auxin biosynthesis. Nature Communications. doi:10.1038/ncomms 9041.

8. Claussen, W. (2005) Proline as a measure of stress in tomato plants. Plant Sci. 168, 241-248.

9. De Rosa Rosa, G., Duncan, D. S., Keen, C. L., Hurley, L. S. (1979) Evaluation of negative staining technique for determination of $\mathrm{CN}$-insensitive superoxide dismutase activity. Biochim. et Biophysica Acta (BBA) Enzymol. 566, 32-39.

10. Du, H., Liu, H., Xiong, L. (2013) Endogenous auxin and jasmonic acid levels are differentially modulated by abiotic stresses in rice. Frontiers Plant Sci. 4, 397.

11. Ellouzi, H., Hamed, K. B., Cela, J., Müller, M., Abdelly, C., Munne-Bosch, S. (2013) Increased sensitivity to salt stress in tocopherol-deficient Arabidopsis mutants growing in a hydroponic system. Plant Signal. Behaviour 8, 2. 
12. Flores, M. I. A., Romero-Gonzalez, R., Garrido-Frenich, A., Vidal, J. L. M. (2011) QuEChERS-based extraction procedure for multifamily analysis of phytohormones in vegetables by UHPLC-MS/MS. J. Sep. Sci. 34, 1517-1524.

13. Gapińska, M., Skłodowska, M., Gabara, B. (2008) Effect of short- and long-term salinity on the activities of antioxidative enzymes and lipid peroxidation in tomato roots. Acta Physiol. Plant. 30, $11-18$.

14. Gossett, D. R., Millhollon, E. P., Lucas, M. C. (1994) Antioxidant response to NaCl stress in salttolerant and salt-sensitive cultivars of cotton. Crop Sci. 34, 706-714.

15. Habig, W. H., Pabst, M. J., Jakoby, W. B. (1974) Glutathione S-transferases: The first enzymatic step in mercapturic acid formation. J. Biol. Chem. 249, 7130-7139.

16. Halliwell, B., Gutteridge, J. M. C. (2007) Free Radical Biology and Medicine. 4. Oxford: Clarendon. pp. 1-777.

17. Havaux, M., Eymery, F., Porfirova, S., Rey, P., Doermann, P. (2005) Vitamin E protects against photoinhibition and photooxidative stress in Arabidopsis thaliana. Plant Cell 17, 3451-3469.

18. Hernandez, J. A., Olmos, E., Corpas, F. J., Sevilla, F., Del Rio, L. A. (1995) Salt-induced oxidative stress in chloroplasts of pea plants. Plant Sci. 105, 151-167.

19. Herzog, V., Fahimi, H. D. (1973) A new sensitive colorimetrical assay for peroxidase, using 3,3-diaminobenzidine as hydrogendonor. Anal. Bioch. 55, 554-562.

20. Jaleel, C. A., Lakshmanan, G. M. A., Gomathinayagam, M., Panneerselvam, R. (2008) Triadimefon induced salt stress tolerance in Withania somnifera and its relationship to antioxidant defense system. South African J. Bot. 74, 126-132.

21. Johnson, C. M., Ulrich, A. (1959) II. Analytical methods foruse in plant analysis. California Agricultural Exp. Station Bulletin 766, 30-33.

22. Kumar, S., Singh, R., Nayyar, H. (2012) $\alpha$-Tocopherol application modulates the response of wheat (Triticum aestivum $\mathrm{L}$.) seedlings to elevated temperatures by mitigation of stress injury and enhancement of antioxidants. J. Plant Growth Regul. 32, 307-314.

23. Laemmli, U. K. (1970) Cleavage of structural proteins during the assembly of the head bacteriophage T4, Nature 227, 680-685.

24. Lee, M., Jung, J. H., Han, D. Y., Seo, P. J., Park, W. J., Park, C. M. (2012) Activation of a flavin monooxygenase gene YUCCA7 enhances drought resistance in Arabidopsis. Planta 235, 923-938.

25. Liu, C. M. (2015) Auxin binding protein 1 (ABP1): a matter of fact. J. Integr. Plant Biol. 57, 234-235.

26. Madhava Rao, K. V., Sresty, T. V. (2000) Antioxidative parameters in the seedlings of pigeonpea (Cajanus cajan (L.) Millspaugh) in response to Zn and Ni stresses. Plant Sci. 157, 113-128.

27. Miret, J. A., Munne-Bosh, S. (2015) Redox signaling and stress tolerance in plants: a focus on vitamin E. Annals of the New York Academy of Sci. 1340, 29-38.

28. Munne-Bosch and Falk (2004) New insights into the function of tocopherols in plants. Planta 218, 323-326.

29. Munné-Bosch, S., Peñuelas, J. (2004) Drought-induced oxidative stress in strawberry tree (Arbutus unedo L.) growing in Mediterranean field conditions. Plant Sci. 166, 1105-1110.

30. Naser, V., Shani, E. (2016) Auxin response under osmotic stress. Plant Mol. Biol. doi: 10.1007/ s11103-016-0476-5.

31. Nazar, R., Iqbal, N., Syeed, S., Khan, N. A. (2011) Salicylic acid alleviates decreases in photosynthesis under salt stress by enhancing nitrogen and sulfur assimilation and antioxidant metabolism differentially in two mungbean cultivars. J. Plant Physiol. 168, 807-815.

32. Noctor, G. (2006) Metabolic signaling in defence and stress: the central roles of soluble redox couples. Plant Cell Environ. 29, 409-425.

33. Orabi, S. A., Abdelhamid, M. T. (2014) Protective role of $\alpha$-tocopherol on two Vicia faba cultivars against seawater-induced lipid peroxidation by enhancing capacity of anti-oxidative system. $J$. the Saudi Society of Agricultural Sci. doi: 10.1016/j.jssas.2014.09.001

34. Semida, W. M., Taha, R. S., Abdelhamid, M. T., Rady, M. M. (2014) Foliar-applied $\alpha$-tocopherol enhances salt-tolerance in Vicia faba L. plants grown under saline conditions. South African J. Bot. $95,24-31$. 
35. Shi, H., Chen, L., Ye, T., Liu, X., Ding, K., Chan, Z. (2014) Modulation of auxin content in Arabidopsis confers improved drought stress resistance. Plant Physiol Biochem. 82, 209-217.

36. Sobhanian, H., Razavizadeh, R., Nanjo, Y., Ehsanpaur, A. A., Jazi, R. F., Motamed, N., Komatsu, S. (2010) Proteome analysis of soybean leaves, hypocotyls and roots under salt stres. Proteome Sci. $8-19$.

37. Velikova, V., Yordanov, I., Edreva, A. (2000) Oxidative stress and some antioxidant systems in acid rain-treated bean plants: protective roles of exogenous polyamines. Plant Sci. 151, 59-66.

38. Went, F. W., Thimann, K. V. (1937) Phytohormones. New York: MacMillan. 289 p.

39. Winifred, M., Cort Thelma, S., Vicente Edward, H., Waysek Beverly Williams, D. (1983) Vitamin E content of feed stuffs determined by high-performance liquid chromatographic fluorescence. J. Agricul. Food Chem. 31, 1330-1333. 